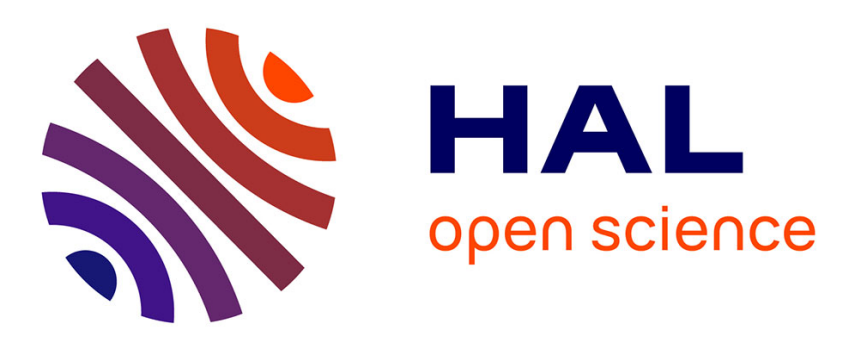

\title{
A glass transition temperature approach for the prediction of the surface stickiness of a drying droplet during spray drying
}

\author{
Benu Adhikari, T. Howes, Didier Lecomte, B. R. Bhandari
}

\section{To cite this version:}

Benu Adhikari, T. Howes, Didier Lecomte, B. R. Bhandari. A glass transition temperature approach for the prediction of the surface stickiness of a drying droplet during spray drying. Powder Technology, 2005, 149 (n²-3), p.168-179. 10.1016/j.powtec.2004.11.007 . hal-01847592

\author{
HAL Id: hal-01847592 \\ https://hal.science/hal-01847592
}

Submitted on 18 Nov 2018

HAL is a multi-disciplinary open access archive for the deposit and dissemination of scientific research documents, whether they are published or not. The documents may come from teaching and research institutions in France or abroad, or from public or private research centers.
L'archive ouverte pluridisciplinaire HAL, est destinée au dépôt et à la diffusion de documents scientifiques de niveau recherche, publiés ou non, émanant des établissements d'enseignement et de recherche français ou étrangers, des laboratoires publics ou privés. 


\title{
A glass transition temperature approach for the prediction of the surface stickiness of a drying droplet during spray drying
}

\author{
B. Adhikari ${ }^{\mathrm{a}}$, T. Howes ${ }^{\mathrm{b}}$, D. Lecomte ${ }^{\mathrm{a}, *}$, B.R. Bhandari ${ }^{\mathrm{c}}$ \\ ${ }^{a}$ Centre for Energy and Environmental Processes, Ecole Des Mines D'Albi Carmaux, Campus Jarlard-Route de Teillet, 81013 Albi CT Cedex 09, France \\ ${ }^{\mathrm{b}}$ School of Engineering, The University of Queensland, St. Lucia, QLD 4072, Australia \\ ${ }^{\mathrm{c}}$ School of Land and Food Sciences, The University of Queensland, St. Lucia, QLD 4072, Australia
}

\begin{abstract}
The development of surface stickiness of droplets of sugar and acid-rich foods during spray drying can be explained using the notion of glass transition temperature $\left(T_{\mathrm{g}}\right)$. In this work, criteria for a safe drying regime have been developed and their physical basis provided. A dimensionless time $(\psi)$ is introduced as an indicator of spray dryability and it is correlated with the recovery of powders in practical spray drying. Droplets with initial diameters of $120 \mu \mathrm{m}$ were subjected to simulated spray drying conditions and their safe drying regime and $\psi$ values generated. The model predicted the recovery in a pilot scale spray dryer reasonably well.
\end{abstract}

Keywords: Spray drying; Stickiness; Safe drying regime; Powder recovery; Glass transition

\section{Introduction}

Stickiness and the subsequent deposition of materials on the dryer surface is regarded as one of the most widespread problems encountered in the spray drying industry [1]. Such deposition causes quality degradation, excessive plant shutdowns, frequent cleaning requirements and safety hazards. Powders of sugar and acid-rich foods such as honey and fruit juices, in their pure form, cannot be easily produced through a spray drying route due to their stickiness [2].

In industrial practice, a sticky point temperature curve is generated and used to develop an operational safety envelope in which the problem of stickiness is minimized [3]. To this end, the sticky point temperature of a powder is determined by subjecting it to a controlled humidity and temperature. The temperature, for a given moisture, at

\footnotetext{
* Corresponding author. Tel.: +33 5634930 93; fax: +33 5634932 43.

E-mail address: lecomte@enstimac.fr (D. Lecomte).
}

which the powder shows maximum resistance to shearing motion in a Lazar [4] type device [5-7] is known as the sticky point temperature. The sticky point temperature represents an upper operating line and the temperature of the drying sample is kept below this.

In the 1990s, the notion of glass transition was introduced to provide a better fundamental understanding and predictability of the sticky point temperature. It is generally accepted that the sticky point temperature lies $10-20{ }^{\circ} \mathrm{C}$ above the glass transition temperature, especially for low molecular weight sugars and carbohydrates $[7,8]$. However, Adhikari et al. [9-12] showed that a maltodextrin drop exhibited peak stickiness at average moisture $(u) \approx 1.0$ and the drop surface became completely non-sticky at $u=0.69$ while drying in a 63 ${ }^{\circ} \mathrm{C}$ and $2.5 \%$ relative humidity air stream. They further showed that the $T_{\mathrm{g}}$ of the drop based on average moistures, $u=1.0$ and $u=0.69$ was -95.9 and $-81.1^{\circ} \mathrm{C}$, respectively, and that the drop surface was completely non-sticky even when the drop temperature was about $138{ }^{\circ} \mathrm{C}$ above this glass transition temperature. These findings cannot be explained based on the sticky point temperature concept. This concept fails to explain the stickiness (adhesion) of foods on the 
equipment surfaces for three reasons. Firstly, the results obtained from sticky point tests are drawn from experiments carried out from powders with moistures $(u)$ below 0.1 and it is not reported that these results can be extrapolated to higher moistures. Secondly, in the sticky point tests, the cohesive force between the particle surfaces is dominant rather than the adhesive force at the food-equipment interface. Thirdly, the samples in sticky point tests are equilibrated to have uniform moisture, while sharp moisture gradients exist in a drop subjected to convective drying. Hence, it is unlikely that the conclusions drawn from sticky point tests are automatically applicable to explain the surface stickiness of drops subjected to dynamic drying conditions.

Langrish and Fletcher [13,15] and Harvie et al. [14] have used computational fluid dynamics to optimally design spray dryers for food products including sticky ones. Their approach takes into account the particle trajectories, air flow pattern and deposition of particles on the dryer surface. However, the wall disposition of a particle is a strong function of its material properties, especially the dynamic surface properties causing stickiness. These authors rely on the information gained by sticky point approach, which does not provide the stickiness history of a drying droplet as it dries [9-12].

Adhikari et al. [11,12] proposed a model to predict the surface stickiness of droplets of sugar-rich foods in spray drying conditions based on the drying kinetics and $T_{\mathrm{g}}$ of the surface layer. A prediction was made on how strongly the drop is likely to adhere to the dryer surface upon impact. Furthermore, they proposed a dimensionless time, $\psi$, as an indicator of the degree of spray dryability of a sticky material. The results were verified using an in situ stickiness testing device, which operated under convective drying conditions. However, they did not demonstrate how their findings would be realized in spray drying operations.

This paper aims at relating the surface stickiness of droplets, subjected to a spray drying environment, to their surface layer $T_{\mathrm{g}}$ and powder recovery in spray dryers. Section 2 of this paper briefly presents the assumptions made and model used for prediction of surface stickiness. This section also presents and discusses key physical parameters, namely effective moisture diffusivity, water activity and mixture $T_{\mathrm{g}}$, which are required for the implementation of the model. Section 3 presents and discusses the results obtained from modelling and compares these with the recovery of powders obtained from a pilot scale spray dryer. The final section summarizes and concludes the paper.

\section{The model and the physical parameters}

\subsection{The model}

This model relates distribution of moisture and $T_{\mathrm{g}}$ within a drop and drop temperature history to droplet/particle stickiness. The surface layer $T_{\mathrm{g}}$ is used as indicator of surface stickiness.

The following key assumptions were made to develop the model

- The drop is a non-hollow sphere.

- It shrinks uniformly with loss of water (ideal shrinkage).

- There are no temperature gradients within the drop.

- Moisture transfer within the drop is by molecular diffusion and species convection.

- Heat transfer to the drop is solely by convection.

- There is no segregation of solids within the droplet/ particle.

- The drop is pseudo-binary in composition (i.e. water and solids).

\subsubsection{Prediction of moisture, drop temperature and glass transition temperature histories}

The distribution of moisture, $u(r, t)$, within a drying drop, is computed by solving the convective-diffusion Eq. (1) [16] in a solute-fixed coordinate system. The moisture history is obtained by averaging the moisture distributions. The temperature history is predicted by Eq. (2), which was developed from an energy balance around the drop. The flux $(F)$ of water leaving the drop surface at a given time is given by Eq. (3).

$\frac{\partial u}{\partial t}=\frac{\partial}{\partial z}\left(D_{\mathrm{w}}(u, T) C_{\mathrm{s}}^{2} r^{4} \frac{\partial u}{\partial z}\right)$

$\frac{\mathrm{d} T_{\mathrm{d}}}{\mathrm{d} t}=\frac{4 \pi R^{2}\left\lfloor h_{\mathrm{g}} *\left(T_{\mathrm{a}}-T_{\mathrm{d}}\right)-\Delta H_{\mathrm{v}} F\right\rfloor}{m_{\mathrm{s}}\left(u C_{\mathrm{p}, \mathrm{w}}+C_{\mathrm{p}, \mathrm{s}}\right)}$

$F=K_{\mathrm{g}} * \frac{M_{\mathrm{w}}}{R_{\mathrm{G}}} \frac{P_{\mathrm{T}}}{T_{\mathrm{av}}} \ln \left(\frac{1-P_{\mathrm{v}, \mathrm{db}} / P_{\mathrm{T}}}{1-a_{\mathrm{w}} P_{\mathrm{vs}, \mathrm{Td}} / P_{\mathrm{T}}}\right)$

$D_{\mathrm{w}}(u, T), u, C_{\mathrm{s}}$ and $r$ in Eq. (1) are the moisture diffusivity $\left(\mathrm{m}^{2} / \mathrm{s}\right)$, moisture $(\mathrm{kg}$ water $/ \mathrm{kg}$ solid), concentration of solid in solution $\left(\mathrm{kg} / \mathrm{m}^{3}\right)$ and radial distance $(\mathrm{m})$, respectively. $z$ is the spatial variable in a solute-fixed coordinate system, which is defined by Eqs. (4) and (5) below. $R, F, m_{\mathrm{s}}, C_{\mathrm{p}, \mathrm{s}}$ and $C_{\mathrm{p}, \mathrm{w}}$ in Eq. (2) are the drop radius (m), flux of water $\left[\mathrm{kg} /\left(\mathrm{m}^{2} \mathrm{~s}\right)\right]$ leaving the drop surface, mass of solids $(\mathrm{kg})$, specific heat capacity of the solids and the water $\left[\mathrm{J} /\left(\mathrm{kg}{ }^{\circ} \mathrm{C}\right)\right]$, respectively. $\Delta H_{\mathrm{v}}$ is the latent heat of vaporization of water $(\mathrm{J} / \mathrm{kg})$. Similarly, $h_{\mathrm{g}}{ }^{*}, T_{\mathrm{a}}$ and $T_{\mathrm{d}}$ are the heat transfer coefficient $\left[\mathrm{W} /\left(\mathrm{m}^{2}{ }^{\circ} \mathrm{C}\right)\right]$ corrected for high flux, temperature of the bulk air $\left({ }^{\circ} \mathrm{C}\right)$ and temperature of the drop $\left({ }^{\circ} \mathrm{C}\right)$, respectively. In Eq. (3), $K_{\mathrm{g}}{ }^{*}$ is the mass transfer coefficient $(\mathrm{m} / \mathrm{s})$ corrected for high flux, $M_{\mathrm{w}}$ is the molecular weight of water $(\mathrm{kg} / \mathrm{kg} \mathrm{mol}), R_{\mathrm{G}}$ is the gas constant $\left[\mathrm{kg} \mathrm{m} /\left(\mathrm{s}^{2} \mathrm{~kg}\right.\right.$ mol K)$], P_{\mathrm{T}}$ is the atmospheric pressure $(\mathrm{Pa}), T_{\mathrm{av}}$ is the film temperature $\left[\left(T_{\mathrm{a}}+T_{\mathrm{d}}\right) / 2\right] . P_{\mathrm{v}, \mathrm{db}}$ and $P_{\mathrm{vs}, \mathrm{Td}}$ are the vapour pressure at air temperature and 
saturated vapour pressure at drop temperature, respectively. $a_{\mathrm{w}}$ is the water activity.

$\frac{\mathrm{d} z}{\mathrm{~d} r}=C_{\mathrm{s}} r^{2}$

$4 \pi Z=m_{\mathrm{s}}=4 \pi \int_{0}^{R} C_{\mathrm{s}} r^{2} \mathrm{~d} r$

$(4 \pi Z)$ represents the mass of the dry solid $(\mathrm{kg})$ in the drop, $m_{\mathrm{s}}$, which does not change with time. The numerical solution of Eq. (1) requires one initial and two boundary conditions, while the solution of Eq. (2) requires an initial condition only. The initial and boundary conditions are given in Eqs. (6)-(8).

IC $: t=0,0<z<Z, u=u_{\mathrm{o}}$ and $T_{\mathrm{d}}=T_{\mathrm{d}, \mathrm{o}}$

$B C_{1}: t>0, z=0, \partial u / \partial z=0$

$B C_{2}: t>0, z=Z, D_{\mathrm{w}}(u, T) C_{\mathrm{s}}^{2} R^{2} \frac{\partial u}{\partial z}=-F$

$u_{\mathrm{o}}$ and $T_{\mathrm{d}, \mathrm{o}}$ are the initial moisture content and temperature of the drop, respectively. The first boundary condition reflects the symmetry at the centre of the drop and the second boundary condition states that the amount of water leaving the drop surface equals the diffusive flux at the surface.

The glass transition temperature, $T_{\mathrm{g}}$, of a solid-water mixture is a strong function of water concentration. Once the distribution of moisture $(u)$ within a drying drop is known through the solution of Eq. (1), the distribution of $T_{\mathrm{g}}$ within the drop can be determined using the Gordon-Taylor equation [17], re-written in terms of moisture $(u)$, shown in Eq. (9).

$T_{\mathrm{g}}(u)=\frac{T_{\mathrm{g}, \mathrm{s}}+K T_{\mathrm{g}, \mathrm{w}} u}{1+K u}$

$K$ is the solid-water binary constant, which has to be determined experimentally.

The numerical solution of Eqs. (1) and (2) along with Eq. (9) has been detailed elsewhere [11,18]. The computer codes were written in MATLAB version 5.2 (Mathworks USA) [18].

\subsection{The physical parameters}

\subsubsection{Effective moisture diffusivity}

Prediction of the drying kinetics of sugar and acid-rich foods requires information regarding moisture diffusivity because their drying behavior is diffusion controlled [19]. In this study, Yamamoto's simplified procedure [19,20], based on the regular regime approach, was employed to determine the effective moisture diffusivity.

Thin slab drying was carried out in an isothermal drying chamber consisting of lower and upper compartments. The chambers were separated by a wire mesh. Temperature control was achieved within $\pm 0.5^{\circ} \mathrm{C}$ using a PID controller. The chamber consisted of a fan, which circulated the air and kept it well mixed in both compartments. The disk containing a thin slab of the sample was kept in the upper one. A sufficient amount of silica gel was kept in the lower chamber, which kept the air dry throughout the experiment. A digital balance (Sartorius CP2243 210 $\pm 0.1 \mathrm{mg}$ ) was used to measure the mass of the drying slab. Circular aluminum disks of $1-3 \mathrm{~mm}$ in depth and $50 \mathrm{~mm}$ in diameter were used to prepare thin slabs of the samples. Sucrose (Saint Louis Sugar, France) and maltodextrin of dextrose equivalent 5 (Roquette Freres, France) were mixed in a solid ratio of 60:40 and gelled with the desired amount of water. $0.5 \%$ sodium alginate (Merck Prolabo) was used as a gelling agent. Details of the experimental procedure are given elsewhere [19].

Fig. 1 presents a representative of results obtained when isothermal drying experiments were carried out at 30 and 50 ${ }^{\circ} \mathrm{C}$ in the 3-mm disk. The derivative of the smoothed (fitted) curve was used for determination of the effective moisture diffusivity. In order to obtain sufficient effective diffusivity data points (Fig. 2) for a given isotherm (such as $50{ }^{\circ} \mathrm{C}$ ) $u$ versus $t$ data points of slabs $1-3 \mathrm{~mm}$ (initial thickness) were combined. The algorithm of smoothing and procedure for calculating u versus $D_{\text {eff }}$ from $u$ versus $t$ data are given elsewhere [19,20].

Fig. 2 presents the effective moisture diffusivity $\left(D_{\text {eff }}\right)$ values as a function of $\mathrm{u}$ at 30 and $50{ }^{\circ} \mathrm{C}$. The moisture diffusivity values were further correlated as a function of moisture and temperature for extrapolation and interpolation purposes. The correlation equation (Eq. (10)) was obtained by minimizing the sum of the squares difference between experimental and predicted diffusivities.

$$
\begin{aligned}
D_{\text {eff }}(u, T)= & D_{0,303} \exp \left[-\frac{15}{2+15 u^{1.4}}\right] \\
& \times \exp \left[-\frac{E_{\mathrm{D}}}{R_{\mathrm{G}}}\left(\frac{1}{T_{\mathrm{d}}}-\frac{1}{303.15}\right)\right]
\end{aligned}
$$

$D_{\text {eff,303 }}$ is the effective moisture diffusivity of $\mathrm{S} / \mathrm{M}(60: 40)$ water solution at $30{ }^{\circ} \mathrm{C}(303.15 \mathrm{~K}) . D_{\mathrm{o}, 303}$ is its effective diffusivity at dilute condition at the same temperature. $E_{\mathrm{D}}$ is the activation energy, which was found to be $32.75 \mathrm{MJ} / \mathrm{kg}$ mol. In Eq. (10), $D_{\text {eff }}$ follows Arrhenius type temperature dependence. This form of moisture and temperature dependence of $D_{\text {eff }}$ has been proposed by various authors [20-22].

\subsubsection{Water activity}

Information regarding the vapour pressure at the droplet surface as a function of temperature and moisture is very important for establishing the local equilibrium at a given time. A Dynamic Vapor Sorption device (DVS 1000) was used to determine the desorption isotherms at 30.8 and $40{ }^{\circ} \mathrm{C}$. The DVS is a controlled atmosphere microbalance. In the experiments, variation of the sample mass was monitored as a 


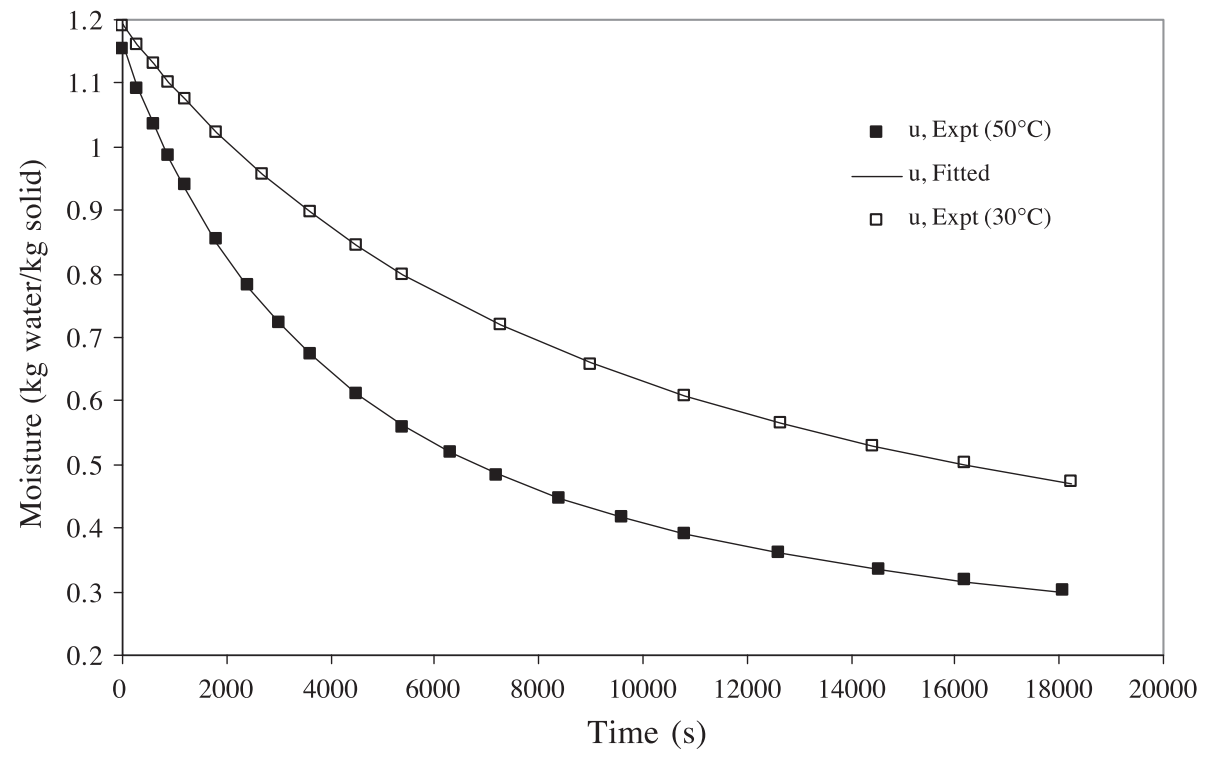

Fig. 1. Typical isothermal drying curves at 30 and $50{ }^{\circ} \mathrm{C}$ for gelled solution sucrose/maltodextrin (60:40). The solid lines are smoothing lines.

function of time over a range of relative humidities by mixing dry air and saturated vapor streams. Samples $(28-37 \mathrm{mg})$ of $40 \%(\mathrm{w} / \mathrm{w}) \mathrm{S} / \mathrm{M}(60: 40)$-water solution were equilibrated at successive levels of relative humidities $(0 \%-90 \%)$ in 11 steps. For each equilibration step, the equilibrium condition was satisfied when the mass of the sample hardly changed with time.

The moisture dependence of the water activity (in one isotherm) can be conveniently correlated using the GAB equation (Eq. (11)).

$u=\frac{C L U_{\mathrm{o}} a_{\mathrm{w}}}{\left(1-L a_{\mathrm{w}}\right)\left(1-L a_{\mathrm{w}}+C L a_{\mathrm{w}}\right)}$

$L, C$ and $U_{\mathrm{o}}$ are the parameters in the GAB model. $U_{\mathrm{o}}$ represents the monolayer moisture content. The temperature dependence of the water activity can be usually correlated through the isosteric heat of sorption.

Fig. 3 presents the desorption isotherms at 30.8 and 40 ${ }^{\circ} \mathrm{C} .0 .5 \%(\mathrm{w} / \mathrm{w})$ sodium alginate was added in the solution to suppress sucrose crystallization. It can be seen from this figure that the isotherms are very close to each other. This shows that, within this temperature range, the temperature dependence on the isotherm is very weak compared to the moisture dependence. Hence, the temperature dependence of the water activity was ignored for the modelling purpose. The moisture dependence of $a_{\mathrm{w}}$ was correlated using the GAB model through a regression analysis. The constants in the GAB equation, $C, L$ and $U_{\mathrm{o}}$ were 5.3, 1 and 0.066, respectively. The regression curve is also presented in Fig. 3. The figure also shows a result for desorption where

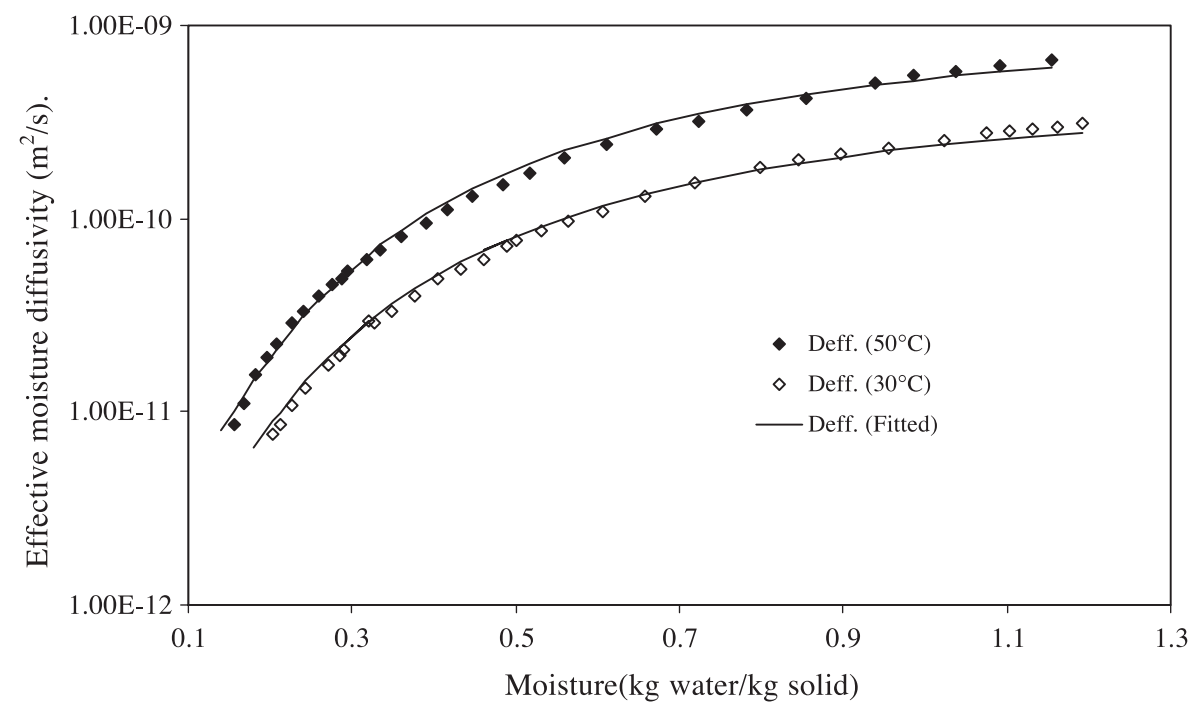

Fig. 2. Effective moisture diffusivity $\left(\mathrm{m}^{2} / \mathrm{s}\right)$ of sucrose/maltodextrin $(60: 40)$ at 30 and $50{ }^{\circ} \mathrm{C}$ based on Yamamoto's simplified procedure. The correlation curves are based on Eq. (9). 


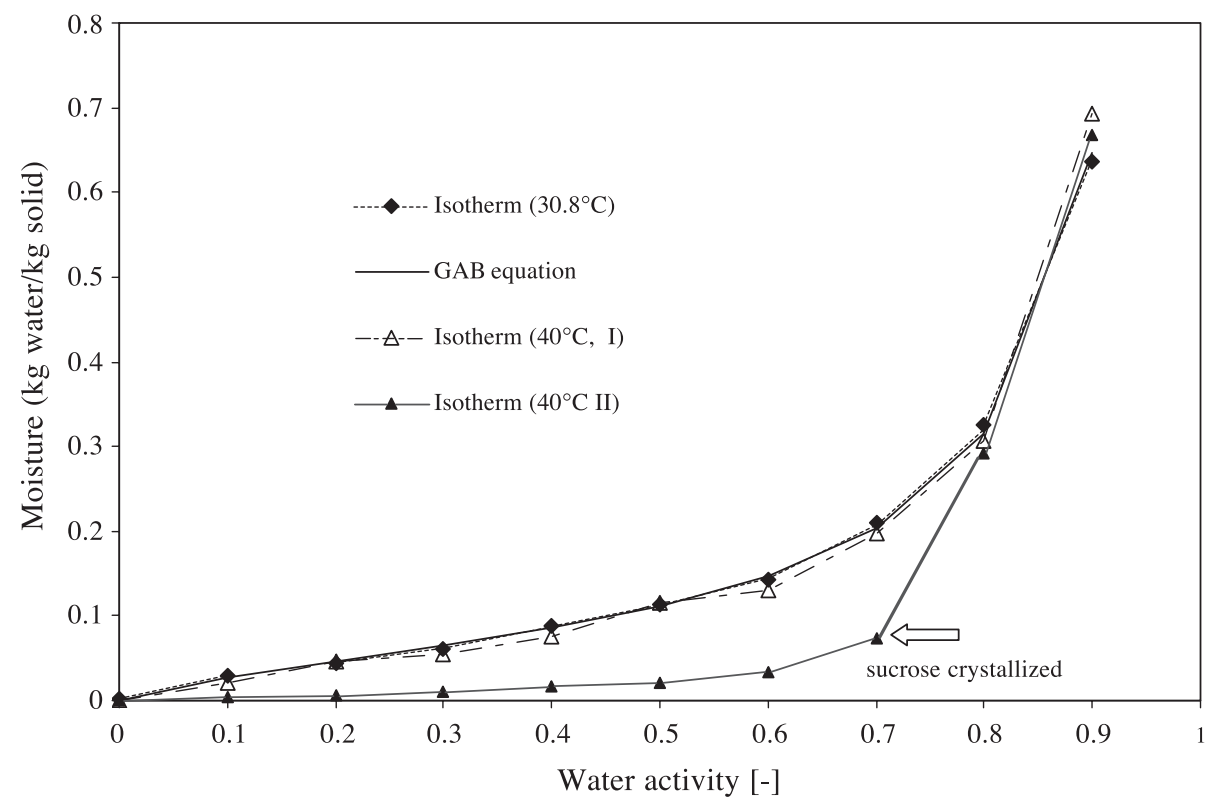

Fig. 3. Desorption isotherm of sucrose/maltodextrin $(60: 40)$-water solution at 30.8 and $40{ }^{\circ} \mathrm{C}$ (isotherm $40{ }^{\circ} \mathrm{C}$ I contains $0.5 \%$ sodium alginate, while $40{ }^{\circ} \mathrm{C}$ II does not).

crystallization was not suppressed. In this case, sucrose was observed to crystallize at $a_{\mathrm{w}} \leq 0.7$ at both the temperatures, introducing significant error, as can be observed in the (40 ${ }^{\circ} \mathrm{C}$, II) isotherm.

\subsubsection{Glass transition temperature}

The glass transition temperature of a ternary component drop can be determined by the Gordon-Taylor equation represented by Eq. (12).

$T_{\mathrm{g}, \mathrm{MSW}}=\frac{x_{\mathrm{M}} T_{\mathrm{g}, \mathrm{M}}+x_{\mathrm{S}} K_{\mathrm{MS}} T_{\mathrm{g}, \mathrm{S}}+x_{\mathrm{W}} K_{\mathrm{MW}} T_{\mathrm{g}, \mathrm{W}}}{x_{\mathrm{M}}+x_{\mathrm{S}} K_{\mathrm{MS}}+x_{\mathrm{W}} K_{\mathrm{MW}}}$

$T_{\mathrm{g}, \mathrm{MSW}}$ is the $T_{\mathrm{g}}\left({ }^{\circ} \mathrm{C}\right)$ of the drop containing maltodextrin, sucrose and water. $K_{\mathrm{MS}}, K_{\mathrm{MW}}$ and $K_{\mathrm{SW}}$ are the dimensionless proportionality constants for binary maltodextrinsucrose, maltodextrin-water and sucrose-water, respectively. $T_{\mathrm{g}, \mathrm{M}}, T_{\mathrm{g}, \mathrm{S}}$ and $T_{\mathrm{g}, \mathrm{W}}$ are the $T_{\mathrm{g}}$ of anhydrous maltodextrin, sucrose and pure water, respectively. The values of $T_{\mathrm{g}}$ and binary $K$ are presented in Table 1 [23]. $x_{\mathrm{M}}$, $x_{\mathrm{S}}$ and $x_{\mathrm{W}}$ are the mass fractions of maltodextrin, sucrose and water in the mixture.

Table 1

Glass transition temperature $\left(T_{\mathrm{g}}\right)$ of anhydrous samples and binary $K$ values for Gordon-Taylor equation [17]

\begin{tabular}{ll}
\hline Sample & $T_{\mathrm{g}}\left({ }^{\circ} \mathrm{C}\right)$ or $K$ \\
Water & $-135[30]$ \\
Sucrose & 65 \\
Maltodextrin (DE6) & 205 \\
$K_{\mathrm{MS}}$ & 3.37 \\
$K_{\mathrm{MW}}$ & 7.7 \\
$K_{\mathrm{SW}}$ & 4.42 \\
\hline
\end{tabular}

\section{Results and discussion}

\subsection{Mass and heat Biot numbers}

If the moisture distribution can be predicted reasonably, the glass transition temperature of the surface layer of the drop can be determined and used as an indicator of stickiness, rather than relying on stickiness based on average moisture values. It was found that a drop of $120 \mu \mathrm{m}$ initial diameter usually reached the wall of a pilot scale spray dryer [24]. In the following section, a droplet having initial diameter of $120 \mu \mathrm{m}$ has been subjected to simulated spray drying conditions to predict the development of its surface stickiness and subsequently spray dryability.

In spray drying simulations, a common practice is that the moisture and temperature gradients within the droplets are neglected. This is because the droplets are usually smaller than $200 \mu \mathrm{m}$. Further, if the moisture gradients are considered the models become very complex to solve. Hence, it is worthwhile to assess the extent of mass transfer Biot number $[B i(M)]$, defined by Eq. (13), to see if the moisture gradients within a drop can safely be neglected. Similarly, it is worthwhile to compare the evolution of heat transfer Biot number $[\mathrm{Bi}(H)]$, given by Eq. (14) to assess if the temperature gradient within the drop can be neglected.

$$
\begin{aligned}
& B i(M)=\frac{K_{\mathrm{g}} * R}{3 D_{\mathrm{eff}}} \\
& B i(H)=\frac{h_{\mathrm{g}} * R}{3 k_{\mathrm{drop}}}
\end{aligned}
$$

$K_{\mathrm{g}}$ and $h_{\mathrm{g}}$ are the air side mass transfer $(\mathrm{m} / \mathrm{s})$ and heat transfer coefficients $\left[\mathrm{W} /\left(\mathrm{m}^{2} \mathrm{~s}\right)\right]$, respectively. $k_{\text {drop }}$ is the 
thermal conductivity of the drop/particle $[\mathrm{W} /(\mathrm{m} \mathrm{K})]$. Both $K_{\mathrm{g}}^{*}$ and $h_{\mathrm{g}}^{*}$ for spherical drops were obtained using Ranz and Marshall's correlation [25] after applying corrections for high flux conditions as proposed by Bird et al. [26]. The thermal conductivity of drop was obtained by using parallel model [27] from the thermal conductivities of sucrose, maltodextrin and water.

Fig. 4 presents the variation of $[\mathrm{Bi}(M)]$ and $[\mathrm{Bi}(H)]$ of an initially $120 \mu \mathrm{m}$ droplet of S/M (60:40)-water solution subjected to spray drying conditions of $85^{\circ} \mathrm{C}, 10 \mathrm{~m} / \mathrm{s}$ air velocity and $2.5 \%$ relative humidity. This figure shows that, as the drop dries from $u=1.5$ to $u=0.05,[B i(H)]$ remains in a range from 0.06 to 0.1 . The temperature of the drop rises from 24 to $84.9{ }^{\circ} \mathrm{C}$ within which the rise of $[\mathrm{Bi}(H)]$ is 0.04 , which means that, in this modeling work, the effect of temperature on $[\mathrm{Bi}(H)]$ is insignificant and also that the temperature gradients within the drop can be safely neglected. The $[B i(M)]$, however, ranges from $1.6 \times 10^{6}$ to $5.8 \times 10^{7}$. These large values suggest that the moisture gradients within the drop cannot be ignored. These results are not unexpected because $\mathrm{S} / \mathrm{M}$-water droplets have a very low effective moisture diffusivity (Fig. 2) compared to the diffusivity of water vapor in air.

The high values of $[B i(M)]$ strongly support the fact that the moisture gradients exist in droplets of the size usually found in industrial spray dryers and consequently support the approach adopted in this study that the surface layer $T_{\mathrm{g}}$ of these droplets/particles determines their surface stickiness.

\subsection{The safe drying regime}

In this section, we would like to discuss the criteria required for a droplet/particle surface to enter the safe drying regime. The safe drying regime is the regime $[u$ (average), $T_{\mathrm{d}}$ ] of a drop at which its surface is rendered completely non-sticky and is unable to adhere to the dryer wall, bottom or roof upon approach/impact.

Adhikari et al. $[11,12]$ have stated the criteria for the state of stickiness of a droplet/particle surface as follows. The drop surface is sticky if its surface layer $T_{\mathrm{g}}$ is lower than the drop temperature $\left(T_{\mathrm{d}}\right)$. The drop surface exhibits peak tendency to stick when its surface layer $T_{\mathrm{g}}$ reaches or just crosses the drop temperature $\left(T_{\mathrm{d}}\right)$. The drop surface becomes completely non-sticky when the surface layer $T_{\mathrm{g}}$ is higher than the drop temperature $\left(T_{\mathrm{d}}\right)$ by $10{ }^{\circ} \mathrm{C}$. Hence, a safe drying regime can be defined as the regime where $T_{\mathrm{g}}$ of the surface layer is $\geq T_{\mathrm{d}}+10{ }^{\circ} \mathrm{C}$. These criteria were based on experimental measurements of surface stickiness.

The above criteria are not in accordance with the observations from sticky point temperature tests that a powder is sticky at its sticky point temperature which is found to be $T_{\mathrm{g}}+10-20{ }^{\circ} \mathrm{C}$. It is because the sticky point temperature measures the cohesive (or caking) property of powders, which is in essence the force of attraction between similar surfaces. The stickiness related to spray dryer deposition should be the adhesive force at the drop (particle)-equipment interface. The existence of sticky point temperature at $10-20{ }^{\circ} \mathrm{C}$ above the average $T_{\mathrm{g}}$ has been drawn from powders with moisture below $u=0.1$. In situ experimental evidence $[9,10]$ suggests that conclusions drawn from the sticky point tests are not applicable to drops (or particles) of low molecular weight sugars, carbohydrates and their mixtures (skin forming materials) subjected to convective drying. Furthermore, the sticky point tests are carried out in a static mode with respect to moisture, i.e. the powder is equilibrated to uniform moisture, while droplets/ particles during spray drying are dynamic with respect to moisture, i.e. the moisture changes spatially as well as temporally. Because of these fundamentally different conditions, it is expected that the information derived from the

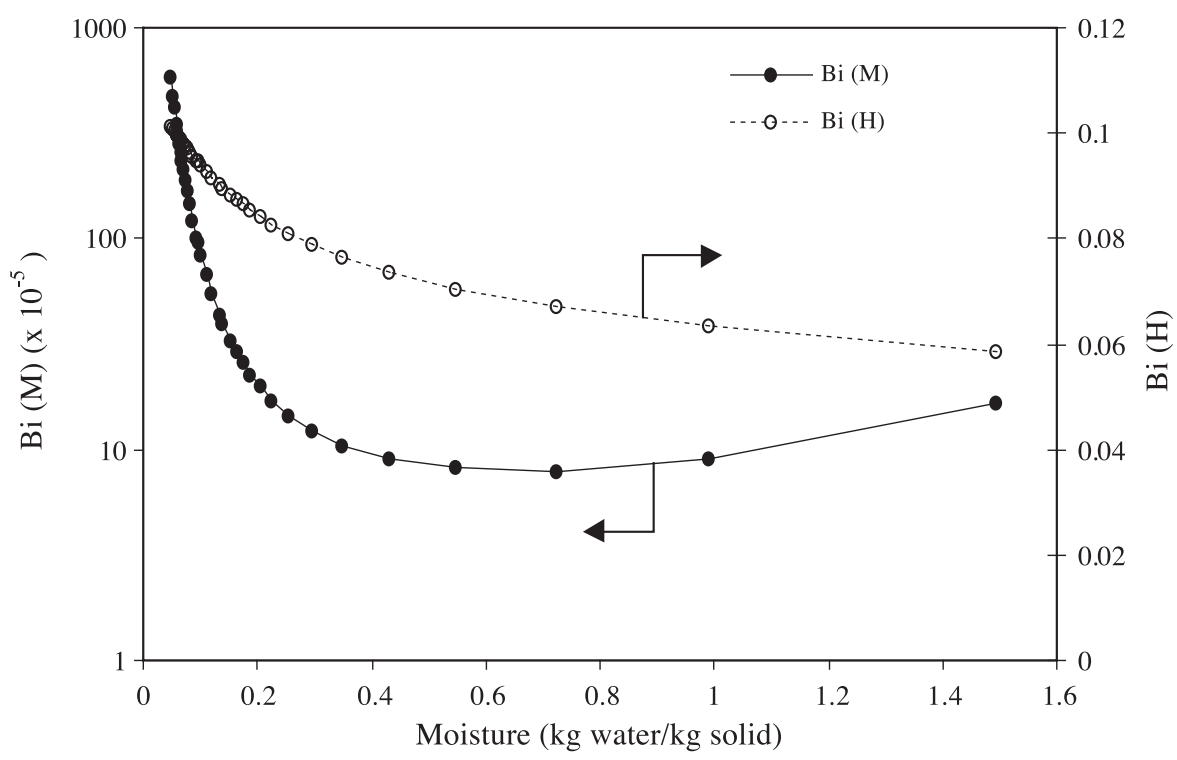

Fig. 4. Simulated mass and heat Biot numbers for a $120-\mu \mathrm{m}$ drop at $85{ }^{\circ} \mathrm{C}, 10 \mathrm{~m} / \mathrm{s}$ air velocity, $2.5 \%$ relative humidity at moisture rage of $u=1.5-0.05$. 
sticky point tests was not applicable to the cases where the dynamic surface property of the drying drop differed from its bulk properties.

The definition of a sticky and safe (non-sticky) drying regime based on the surface layer $T_{\mathrm{g}}$ gives rise to questions such as: Why does the drop surface shows a peak tendency to stick when the drop temperature $\left(T_{\mathrm{d}}\right) \approx$ surface layer $T_{\mathrm{g}}$ ? What is the physical significance of the $10{ }^{\circ} \mathrm{C}$ offset that is provided as a criterion for a drop to enter the safe drying regime? The answer to the first question lies in the fact that $T_{\mathrm{g}}$ is a measure of a phase transition phenomena, where a sticky (rubbery) material becomes non-sticky glass. Glass transition occurs across a range of temperatures, $T_{\mathrm{g}}$ onset to $T_{\mathrm{g} \text { endset }}$ and that $T_{\mathrm{g} \text { endset }}-T_{\mathrm{g} \text { onset }}$ ranges from 10 to $30{ }^{\circ} \mathrm{C}$ [28]. Let us imagine that a liquid like (sticky) material is moving towards the solid like glass (non-sticky state). When it is in a liquid phase $\left(T_{\mathrm{d}} \gg\right.$ surface $\left.T_{\mathrm{g}}\right)$, it exhibits low cohesive strength (high fluidity) compared to the adhesive strength at the droplet-equipment interface. The force required to separate the droplet from the equipment surface will be small as breakage (cohesive failure) will occur within the material. When it is close to $T_{\mathrm{g} \text { endset }}$, the cohesive strength of the material will increase substantially due to decreased fluidity. This will require a higher force to separate a droplet/particle from the material surface. When the material surface enters the phase transition region, it achieves a cohesive strength equal to or slightly higher than the adhesive strength at the droplet-equipment interface and the material fails adhesively. At this state, a peak force is required to separate the droplet/particle from the equipment surface. When the material temperature falls below $T_{\mathrm{g}}$ onset, it completes the transition and becomes glassy. In this state, the material no longer sticks to the probe surface and no force will be required to separate the particle from the dryer wall. The second question can also be answered using $T_{\mathrm{g}}$. Since the glass transition occurs over a temperature range, a time scale is required to complete the process. It is reasonable to provide a temperature offset that will result in a time scale of sufficient length to complete the transition. A temperature offset of $10{ }^{\circ} \mathrm{C}$ translates to a time scale sufficient for a maltodextrin drop to reach a state of nonadhesion (non-sticky) from its maximally sticky state [11]. The need of the temperature offset can also be explained from the work of Kudra [29] who found that, for pasty materials, stickiness occurred over a temperature range, rather than at a particular point, i.e. stickiness is a transition phenomenon encompassing a region rather than a sharp point. Furthermore, the need of a temperature offset (practically a time length) can also be explained from the fact that the core of a drying drop remains highly viscous with sufficiently high moisture when the surface of the drop attains a glassy state (indicated by peak force and adhesive failure). The process of outward diffusion of moisture is continuing and the glassy (surface) layer is not sufficiently thick when the peak force is observed. The time scale provided by the $10{ }^{\circ} \mathrm{C}$ offset allows the glassy surface layer to grow to sufficient thickness so that the drop surface attains a sufficiently stable (dynamic) non-adhesion state.

Adhikari et al. [11] also introduced a dimensionless time $\psi$, defined as the ratio of the time required to enter the safe drying regime $\left(t_{\mathrm{NS}}\right)$ to the time needed to achieve the (desired) final average moisture content $\left(t_{\text {total }}\right) . \psi$ is an important indicator of the degree of difficulty with which a drop can enter a safe drying regime. If $\psi$ is $>1$, the drop does not enter the safe drying regime. If the $\psi=1$, it is a limit or a situation at which the drop enters the safe drying regime towards the completion of drying, that is, it is a cut-off point. If $\psi<1$, the drop enters the safe drying regime. The smaller the $\psi$ ratio is, the earlier the drop enters the safe drying regime.

The definition of the safe drying regime and its indicator $(\psi)$ need to be correlated with the degree of easiness or difficulty in practical spray drying. The percent (\%) powder recovery, defined by the ratio of powder recovered to the total solids in the feed times $100 \%$, is commonly used as a measure of spray drying performance [2,24]. Fifty percent $(50 \%)$ recovery has been used to define a marginally successful spray drying in a pilot scale dryer [2]. From the definitions of recovery and $\psi$, these two quantities can be interrelated as follows: if $\psi=1$, it corresponds to the $50 \%$ recovery and indicates a marginally successful spray drying; if the $\psi>1$, the recovery will be $<50 \%$. The greater the $\psi$ value is, the lower will be the recovery. If $\psi<1$, the recovery will be $>50 \%$. The lower the $\psi$ value is, the higher will be the recovery. Henceforth, recovery lower than $50 \%$ is referred to as unsuccessful spray drying, recovery higher than $50 \%$ are referred to as successful spray drying and recovery equal to $50 \%$ are referred to as limiting or marginally successful spray drying.

\subsection{Case I: sucrose/maltodextrin (60:40)}

It is known that a pure sucrose solution could not be successfully spray dried at dryer outlet temperature as low as $63{ }^{\circ} \mathrm{C}$ and relative humidity as low as $2 \%$. Maltodextrin, as a drying aid, would need to be added to produce a powder. What amount of maltodextrin would be optimal for a marginally successful spray drying? The model predictions based on Eqs. (1), (2) and (12) are compared with the powder recovery of a sugar mixture $(\mathrm{S} / \mathrm{M}=60: 40)$ in a pilot scale spray dryer. The physical parameters such $D_{\text {eff, }} a_{\mathrm{w}}$ and $T_{\mathrm{g}}$ diffusivity, water activity and glass transition temperature are provided in Section 2.

Figs. 5 and 6 present the model predicated drop temperature and surface layer $T_{\mathrm{g}}$ of droplets with initial diameters of $120 \mu \mathrm{m}$ subjected to simulated spray drying conditions of 85 and $76{ }^{\circ} \mathrm{C}$ dryer outlet temperatures, respectively. The air velocity and the relative humidity were taken as $10 \mathrm{~m} / \mathrm{s}$ and $2.5 \%$. A temperature range of $65-90{ }^{\circ} \mathrm{C}$ is a common dryer outlet temperature range when drying of sticky materials is considered. The key features of these two figures are summarized in Table 2. It shows the surface layer $T_{\mathrm{g}}, \psi$ values and an assessment of the degree of spray dryability of 


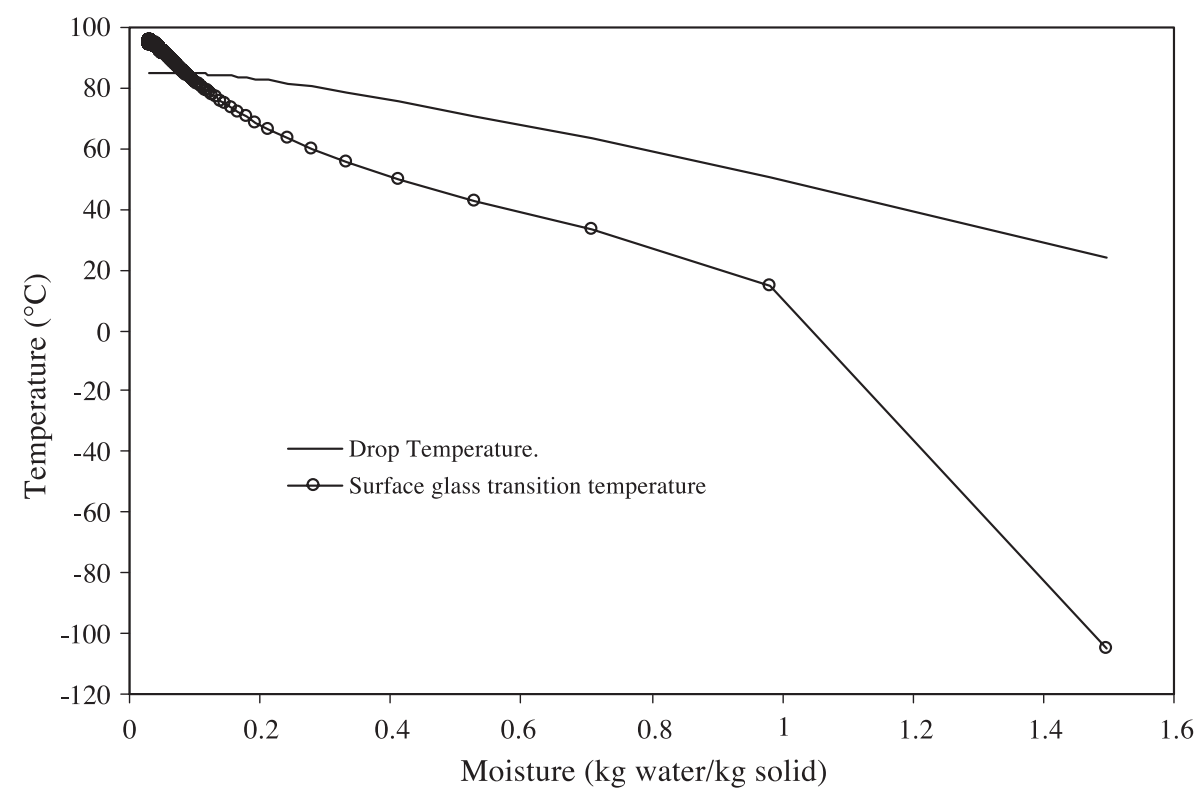

Fig. 5. Surface layer $T_{\mathrm{g}}$ and drop temperature histories of an initially $120 \mu \mathrm{m}$ diameter drop of sucrose (S)/maltodextrin (M), at the ratio of (60:40) solutions $\left(40 \% \mathrm{w} / \mathrm{w}\right.$ solutes initially) simulated at $85{ }^{\circ} \mathrm{C}, 10 \mathrm{~m} / \mathrm{s}$ air velocity and $2.5 \%$ relative humidity.

droplets of S/M (60:40). This table also presents the powder recovery for the drops of the same composition from a pilot scale rotary spray dryer [Niro Anhydro (Lab-1), co-current, cylindrical section: diameter $=1000 \mathrm{~mm}$, height $=750 \mathrm{~mm}$, conical section: height $=850 \mathrm{~mm}]$ maintained at outlet temperature of $85 \pm 0.5$ and $76 \pm 0.5{ }^{\circ} \mathrm{C}$ [24]. The outlet temperature of $76 \pm 0.5{ }^{\circ} \mathrm{C}$ was maintained by introducing cold dehumidified air at the bottom of the dryer. This table shows that the recovery of powder (in the final cyclone) is $45 \%$ at $85{ }^{\circ} \mathrm{C}$ and $55 \%$ at $76^{\circ} \mathrm{C}$. The author reported that an additional $5-6 \%$ of the powder was recovered by lightly sweeping the wall and the bottom of the drier, which should lead to an effective recovery of $50 \%$ at $85{ }^{\circ} \mathrm{C}$ and $60 \%$ at 76 ${ }^{\circ} \mathrm{C}$. According to the criteria laid previously, the former is a marginally successful spray drying while the later is a successful one. The model predictions show that, at $85{ }^{\circ} \mathrm{C}$, $\psi=1$ (surface $T_{\mathrm{g}}$ just reaches $T_{\mathrm{d}}+10{ }^{\circ} \mathrm{C}$ ), suggesting that the recovery will be $50 \%$. This suggests that the model is predicting the degree of spray dryability well. Further, at 76 ${ }^{\circ} \mathrm{C}, \psi=0.173$ indicates that the droplet (particle) enters the

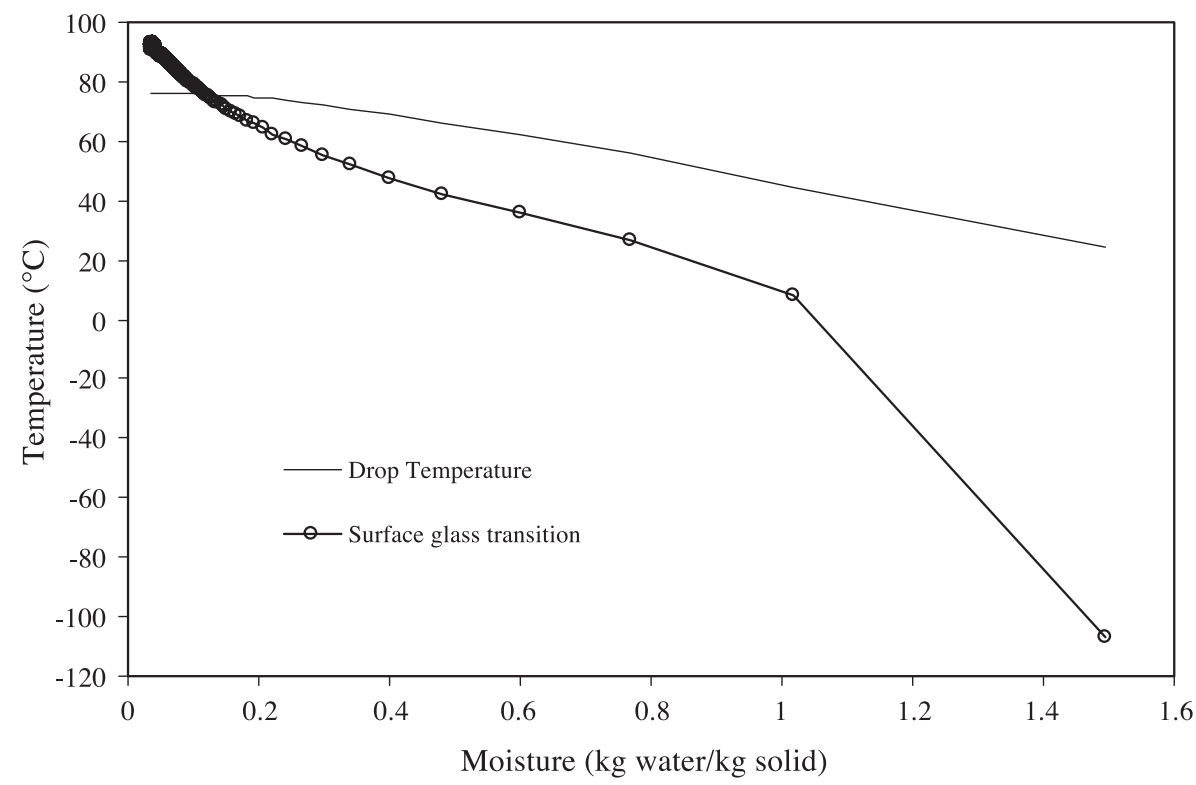

Fig. 6. Surface layer $T_{\mathrm{g}}$ and drop temperature histories of an initially $120 \mu \mathrm{m}$ diameter drops of sucrose (S)/maltodextrin (M), at the ratio of (60:40) solutions $\left(40 \% \mathrm{w} / \mathrm{w}\right.$ solutes initially) simulated at $76{ }^{\circ} \mathrm{C}, 10 \mathrm{~m} / \mathrm{s}$ air velocity and $2.5 \%$ relative humidity. 
Table 2

Comparison of model predictions for droplets $[\mathrm{S} / \mathrm{M}(60: 40)]$ at 85 and $76{ }^{\circ} \mathrm{C}$ with the product recovery obtained at the same drying condition in a pilot scale spray dryer

\begin{tabular}{|c|c|c|c|c|c|}
\hline \multicolumn{6}{|c|}{ Model predictions from this study (relative humidity of air $=2.5 \%$ ) } \\
\hline Dryer outlet temp. $\left({ }^{\circ} \mathrm{C}\right)$ & Moisture $(u)$ range & Final $T_{\mathrm{d}}\left({ }^{\circ} \mathrm{C}\right)$ & Final surface layer $T_{\mathrm{g}}\left({ }^{\circ} \mathrm{C}\right)$ & $(\psi)=t_{\mathrm{NS}} / t_{\text {total }}$ & Remarks \\
\hline 85 & $1.5-0.028$ & 84.9 & 95.0 & 1 & marginally successful spray drying \\
\hline 76 & $1.5-0.035$ & 76.0 & 92.7 & 0.173 & successful spray drying \\
\hline \multicolumn{6}{|c|}{ Results from pilot scale spray dryer [24] } \\
\hline Dryer outlet temp. $\left({ }^{\circ} \mathrm{C}\right)$ & \multicolumn{2}{|c|}{ Final sample moisture $(u)$} & \multicolumn{2}{|c|}{ Powder recovery $(\%)$} & Remarks \\
\hline $85 \pm 0.5$ & \multicolumn{2}{|c|}{$0.025 \pm 0.003$} & \multicolumn{2}{|l|}{$45+6=51$} & - \\
\hline $76 \pm 0.5$ & \multicolumn{2}{|c|}{$0.024 \pm 00.3$} & \multicolumn{2}{|l|}{$54+6=60$} & Cooling air at the dryer bottom \\
\hline
\end{tabular}

safe drying regime at $17.3 \%$ of total drying time which according to the previously set criteria constitutes a successful spray drying. This prediction agrees well with the experimental result of $60 \%$ powder recovery. These comparisons show that the model, based on the surface layer $T_{\mathrm{g}}$ of a drying drop, successfully predicts degree of spray dryability of sugar-rich foods in practical spray drying operations.

\subsection{Case II: various sugars/maltodextrin ratios}

Fig. 7 presents the simulated drop temperature and surface layer $T_{\mathrm{g}}$ for $120 \mu \mathrm{m}$ droplet containing sugars (fructose + glucose + sucrose)/maltodextrin at the ratio of 60:40 subjected to $65{ }^{\circ} \mathrm{C}, 4 \%$ relative humidity and $1 \mathrm{~m} /$ $\mathrm{s}$ air velocity. All the physical parameters such as $D_{\text {eff }}$, mixture $T_{\mathrm{g}}$ and mixture $a_{\mathrm{w}}$ were determined using values of corresponding pure components and water using a mass weighted mean rule. These parameters and the procedure for obtaining the mixture-parameters are reported elsewhere $[11,12]$. The results of the simulation for above sugars/ maltodextrin ratios of 60:40 and 55:45 and (glucose+sucrose)/maltodextrin ratios of $68: 32$ and $63: 37$ are presented in Table 3.

Fig. 7 and Table 3 show that the surface layer $T_{\mathrm{g}}$ for sugars/maltodextrin droplet with the ratio of 60:30 has remained within $T_{\mathrm{d}}+10{ }^{\circ} \mathrm{C}$, which, according to the safe drying criteria, has not entered the safe drying regime. In this case, $\psi>1$ and hence is a typical case of unsuccessful spray drying. From Table 3, it can be seen that only $28 \%$ of the powder was recovered in a pilot scale spray dryer when dryer outlet temperature was maintained at $65 \pm 2{ }^{\circ} \mathrm{C}$. When the ratio was maintained at $(55: 45), \psi=0.25$ was obtained indicating a successful spray drying. $56 \%$ of powder recovery is consistent with the model prediction. When only sucrose and glucose were mixed with maltodextrin and

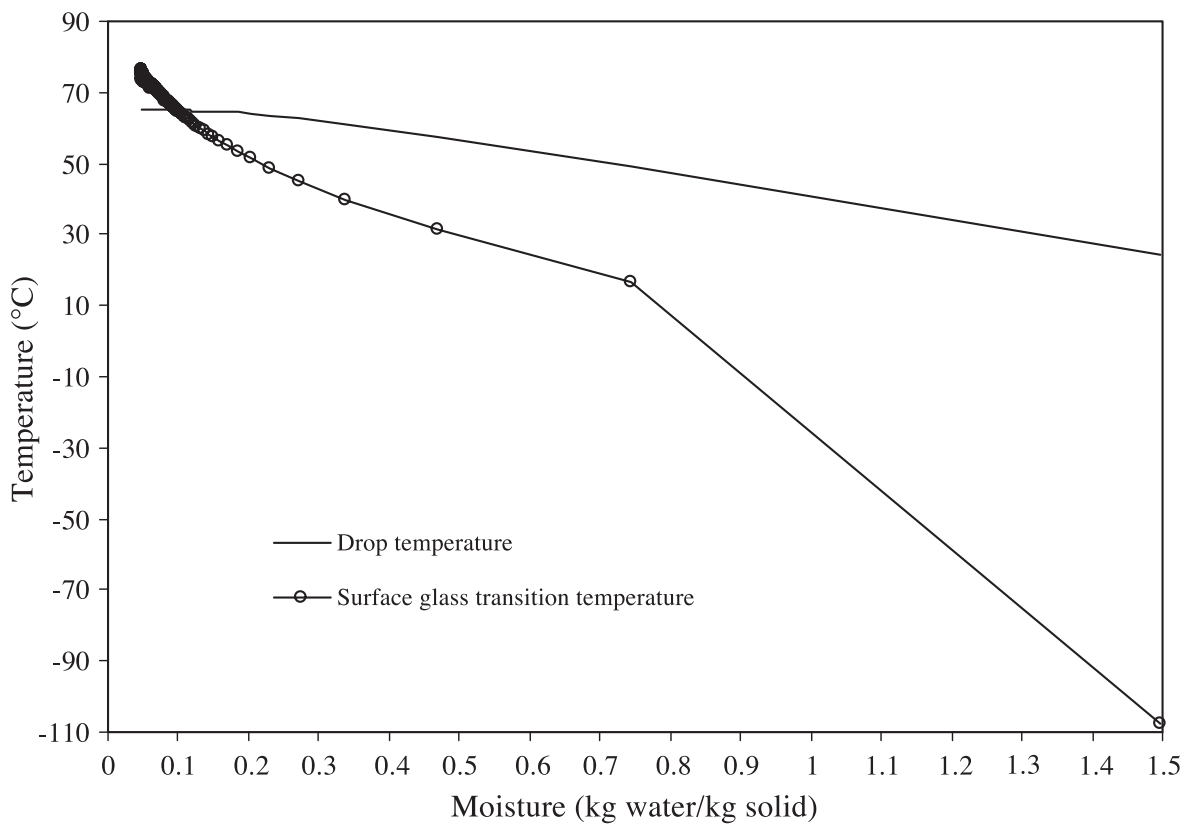

Fig. 7. Surface layer $T_{\mathrm{g}}$ and drop temperature histories of an initially $120 \mu \mathrm{m}$ diameter drop of fructose $(\mathrm{F})+\mathrm{glucose}(\mathrm{G})+\mathrm{sucrose}(\mathrm{S})$ and maltodextrin $(\mathrm{M})$ at ratio of $(60: 40)$ simulated at $65{ }^{\circ} \mathrm{C}, 10 \mathrm{~m} / \mathrm{s}$ air velocity and $4 \%$ relative humidity. 
Table 3

Prediction of surface stickiness of initially $120 \mu \mathrm{m}$ diameter drops simulated at $65{ }^{\circ} \mathrm{C}, 10 \mathrm{~m} / \mathrm{s}$ air velocity, $4 \%$ relative humidity

\begin{tabular}{|c|c|c|c|c|c|}
\hline Materials & Dryer outlet temp. $\left({ }^{\circ} \mathrm{C}\right)$ & Moisture $(u)$ range & Final surface layer $T_{\mathrm{g}}\left({ }^{\circ} \mathrm{C}\right)$ & $\psi\left(t_{\mathrm{NS}} / t_{\text {total }}\right)$ & Remarks \\
\hline$(\mathrm{F}+\mathrm{G}+\mathrm{S}) / \mathrm{M}(60: 40)$ & 65 & $1.5-0.045$ & 73.1 & $>1$ & unsuccessful drying \\
\hline$(\mathrm{F}+\mathrm{G}+\mathrm{S}) / \mathrm{M}(55: 45)$ & 65 & $1.5-0.045$ & 81.6 & 0.25 & successful drying \\
\hline$(\mathrm{S}+\mathrm{G}) / \mathrm{M}(68: 32)$ & 65 & $1.5-0.045$ & 69.1 & $>1$ & unsuccessful drying \\
\hline$(\mathrm{S}+\mathrm{G}) / \mathrm{M}(63: 37)$ & 65 & $1.5-0.045$ & 75.5 & 1 & nominally successful drying \\
\hline \multicolumn{6}{|c|}{ Results from pilot scale spray dryer [2] } \\
\hline $\mathrm{F}+\mathrm{G}+\mathrm{S}) / \mathrm{M}(60: 40)$ & \multicolumn{2}{|l|}{$65 \pm 2$} & - & - & 28 \\
\hline$(\mathrm{F}+\mathrm{G}+\mathrm{S}) / \mathrm{M}(55: 45)$ & \multicolumn{2}{|l|}{$65 \pm 2$} & - & - & 56 \\
\hline $\mathrm{S}+\mathrm{G}) / \mathrm{M}(68: 32)$ & \multicolumn{2}{|l|}{$65 \pm 2$} & - & - & 25 \\
\hline$(\mathrm{S}+\mathrm{G}) / \mathrm{M}(63: 37)$ & \multicolumn{2}{|l|}{$65 \pm 2$} & & & 51 \\
\hline
\end{tabular}

Droplets contain fructose $(\mathrm{F})+$ glucose $(\mathrm{G})+\operatorname{sucrose}(\mathrm{S})$ and maltodextrin $(\mathrm{M})$ at various ratios. $t_{\mathrm{NS}}=$ time to enter the non-sticky regime (s), $t_{\text {total }}=$ time required to reach $u=0.045(\mathrm{~s})$.

subjected to the above simulations, the cut off sugars/ maltodextrin ratio for marginal spray drying was found to be (63:37). This ratio produced $51 \%$ powder recovery in the spray drying trial. A slightly higher ratio of these two sugars to maltodextrin, i.e. $(68: 32)$ produced $\psi \gg 1$ and led to a poor recovery of $25 \%$. These comparisons revealed that the safe drying regime criteria, proposed in this study, can follow the powder recovery in spray dryers.

\subsection{Case III: (sugars+acid)/maltodextrin (60:40)}

Fig. 8 presents the simulated drop temperature and surface layer $T_{\mathrm{g}}$ of $120 \mu \mathrm{m}$ diameter drops containing sugars (fructose, glucose and sucrose), citric acid and maltodextrin. Simulated drying conditions are $65{ }^{\circ} \mathrm{C}, 10 \mathrm{~m} / \mathrm{s}$ air velocity and $2.5 \%$ relative humidity. Table 4 summarizes the outcome of these simulations. The mixture $T_{\mathrm{g}}$, mixture effective moisture diffusivity and mixture water activity inherit their concentration dependence from their respective solid--water binary mixtures. Detail of this mixture rule or mass weighted mean rule is provided elsewhere [12]. Furthermore, other input parameters such as specific heat capacity, thermal conductivity of the mixture were also determined using mass weighted mean rule. The values and their correlation equations are also reported elsewhere [11,12].

Fig. 8 and Table 4 show that for a fruit juice/maltodextrin ratio of 60:40, a droplet enters the safe drying regime after $72 \%$ of the total drying time $(\psi=0.72)$. This constitutes a slightly better scenario than the marginally successful spray drying. All the formulations having a higher proportion of maltodextrin than this ratio are expected to produce a successful spray drying. This prediction agrees well with the spray drying of pineapple juice [2] at a dryer outlet temperature of $65 \pm 2{ }^{\circ} \mathrm{C}$, where the powder recovery was

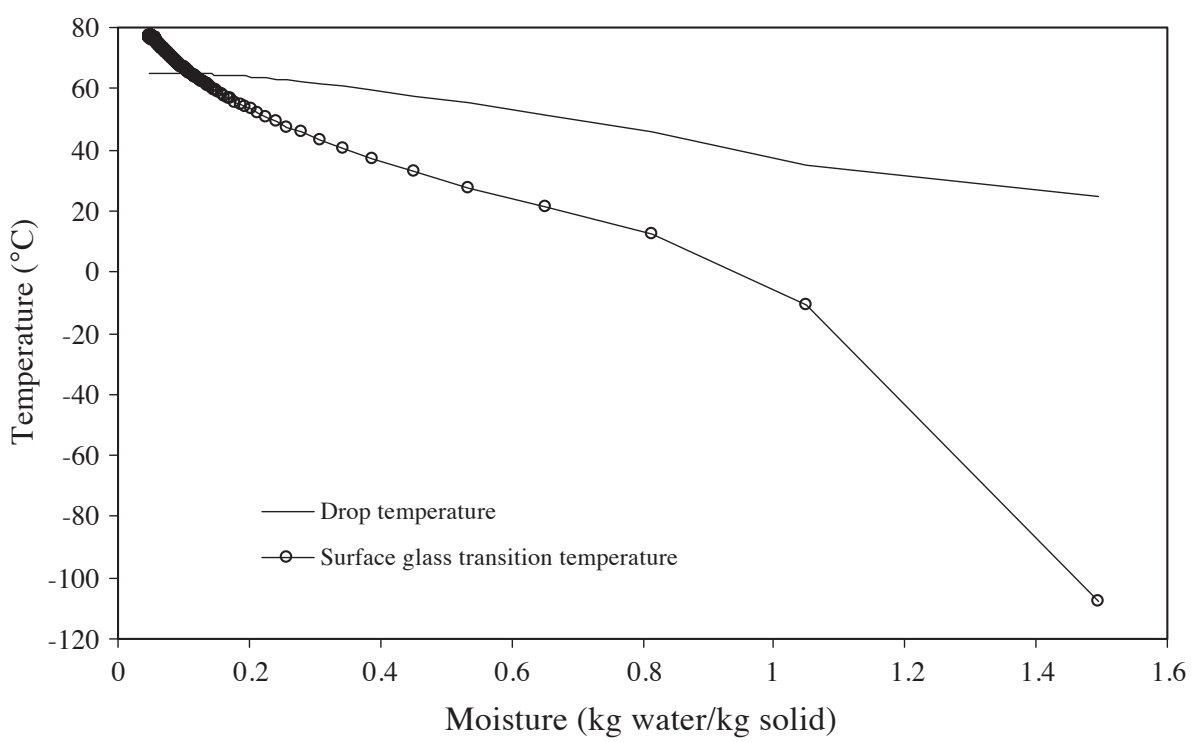

Fig. 8. Surface layer $T_{\mathrm{g}}$ and drop temperature histories of an initially $120 \mu \mathrm{m}$ diameter drop of citric acid (C) fructose (F)+glucose (G) + sucrose (S) and maltodextrin (M) at ratio of $(60: 40)$ simulated at $65{ }^{\circ} \mathrm{C}, 10 \mathrm{~m} / \mathrm{s}$ air velocity and $2.5 \%$ relative humidity. 
Table 4

Prediction of surface stickiness of initially $120 \mu \mathrm{m}$ diameter drops simulated at $65{ }^{\circ} \mathrm{C}, 10 \mathrm{~m} / \mathrm{s}$ air velocity, $2.5 \%$ relative humidity

\begin{tabular}{|c|c|c|c|c|c|}
\hline \multicolumn{6}{|c|}{ Model predictions from this study (relative humidity $=2.5 \%$ ) } \\
\hline Materials & Dryer outlet temp. $\left({ }^{\circ} \mathrm{C}\right)$ & Moisture $(u)$ range & Final surface layer $T_{\mathrm{g}}\left({ }^{\circ} \mathrm{C}\right)$ & $\psi\left(t_{\mathrm{NS}} / t_{\text {total }}\right)$ & Remarks \\
\hline$(\mathrm{C}+\mathrm{F}+\mathrm{G}+\mathrm{S}) / \mathrm{M}(60: 40)$ & 65 & $1.5-0.045$ & 75.9 & 0.72 & successful spray drying \\
\hline Materials & \multicolumn{2}{|c|}{ Dryer outlet temp. $\left({ }^{\circ} \mathrm{C}\right)$} & - & - & Powder recovery $(\%)$ \\
\hline Pineapple juice/M (75:25) & \multicolumn{2}{|l|}{$65 \pm 2$} & - & - & 45 \\
\hline Pineapple juice/M (60:40) & \multicolumn{2}{|l|}{$65 \pm 2$} & - & - & 53 \\
\hline Pineapple juice/M (50:50) & \multicolumn{2}{|l|}{$65 \pm 2$} & - & - & 58.5 \\
\hline
\end{tabular}

Droplets contain citric acid (C)+fructose $(\mathrm{F})+$ glucose $(\mathrm{G})+$ sucrose $(\mathrm{S})$ and maltodextrin $(\mathrm{M})$ at ratios of $(60: 40) . t_{\mathrm{NS}}=$ time to enter the non-sticky regime (s), $t_{\text {total }}=$ time required to reach $u=0.045$ (s).

$53 \%$ when the juice solids to maltodextrin ratio was maintained at 60:40 (Table 4). As shown in Table 4, all drying trials where the juice solids to maltodextrin ratios are higher than this has produced recoveries lower than $50 \%$. Juice solids/maltodextrin ratios smaller than this have resulted in recoveries higher than 50\%. This comparison shows that the notion of glass transition temperature can be applied to successfully predict the stickiness of droplets of sugar and acid-rich foods during spray drying. Furthermore, this notion successfully predicts the powder recovery and degree of spray dryability of sticky food materials.

\section{Summary and conclusions}

The notion of surface glass transition temperature $\left(T_{\mathrm{g}}\right)$ was introduced to characterize the stickiness of a drying drop. The distribution of glass transition temperatures within the drop was predicted using the Gordon-Taylor equation. A safe drying regime was defined as the region where the $T_{\mathrm{g}}$ of the surface layer was more than $10{ }^{\circ} \mathrm{C}$ above the temperature of the drop. A dimensionless time $\psi$, defined as the ratio of time required to enter the safe drying regime to the time needed to achieve the final moisture content, was introduced. It describes the relative ease with which materials can be spray dried and correlates with the recovery of powders in spray dryers. $\psi$ values smaller than 1 correspond to the powder recovery of higher than $50 \%$ (successful spray drying). Values greater than 1 correspond to a powder recovery of lower than $50 \%$ (unsuccessful spray drying). The safe drying regime, the subsequent $\psi$ value and its relationship with the powder recovery were validated from the pilot scale spray drying data of model mixture comprising sucrose/maltodextrin and pineapple juice/maltodextrin in the solid ratio of 60:40 and sugars/maltodextrins in various ratios at different dryer outlet temperatures.

$$
\begin{aligned}
& \text { List of symbols } \\
& a_{\mathrm{w}} \quad \text { water activity } \\
& B i(H) \quad \text { Biot number (heat) } \\
& B i(M) \text { Biot number (mass) } \\
& C \text { parameter in } \mathrm{GAB} \text { equation }
\end{aligned}
$$

$C_{\mathrm{p}} \quad$ specific heat capacity $\left(\mathrm{J} / \mathrm{kg}{ }^{\circ} \mathrm{C}\right)$

$C_{\mathrm{s}} \quad$ concentration of solid $\left(\mathrm{kg} / \mathrm{m}^{3}\right)$

$D_{\mathrm{v}} \quad$ diffusivity of water vapor in air $\left(\mathrm{m}^{2} / \mathrm{s}\right)$

$D_{\text {eff }} \quad$ effective moisture diffusivity $\left(\mathrm{m}^{2} / \mathrm{s}\right)$

$D_{\mathrm{o}} \quad$ effective moisture diffusivity at dilute state $\left(\mathrm{m}^{2} / \mathrm{s}\right)$

$D_{\mathrm{w}} \quad$ moisture diffusivity in solution $\left(\mathrm{m}^{2} / \mathrm{s}\right)$

$E_{\mathrm{D}} \quad$ activation energy $(\mathrm{MJ} / \mathrm{mol})$

$F \quad$ flux of water at the surface of drop containing solids $\left(\mathrm{kg} / \mathrm{m}^{2} \mathrm{~s}\right)$

$h_{\mathrm{g}} \quad$ airside heat transfer coefficient $\left(\mathrm{W} / \mathrm{m}^{2}{ }^{\circ} \mathrm{C}\right)$

$h_{\mathrm{g}}^{*} \quad$ corrected gas side heat transfer coefficient $\left(\mathrm{W} / \mathrm{m}^{2}{ }^{\circ} \mathrm{C}\right)$

$K$ proportionality constant in Gordon-Taylor equation

$K_{\mathrm{g}} \quad$ mass transfer coefficient in air phase $(\mathrm{m} / \mathrm{s})$

$k_{\text {drop }} \quad$ thermal conductivity of the drop/particle $\left(\mathrm{W} / \mathrm{m}{ }^{\circ} \mathrm{C}\right)$

$L \quad$ Parameter in GAB equation

$m_{\mathrm{s}} \quad$ bone dry solid mass $(\mathrm{kg})$

$M_{\mathrm{w}} \quad$ molecular weight of water $(\mathrm{kg} / \mathrm{kg} \mathrm{mol})$

$P_{\mathrm{T}} \quad$ total atmospheric pressure $(\mathrm{Pa})$

$P_{\mathrm{v}, \mathrm{db}} \quad$ vapour pressure at air temperature $(\mathrm{Pa})$

$P_{\mathrm{vs}, \mathrm{Td}} \quad$ saturated vapour pressure at drop temperature $(\mathrm{Pa})$

$R \quad$ radius of drop (m)

$R_{\mathrm{G}} \quad$ universal gas constant $\left[\mathrm{kg} \mathrm{m}^{2} /\left(\mathrm{s}^{2} \mathrm{~kg} \mathrm{~mol} \mathrm{~K}\right)\right]$

$r \quad$ radial distance $(\mathrm{m})$

$T$ temperature $\left({ }^{\circ} \mathrm{C}\right.$ or $\left.\mathrm{K}\right)$

$T_{\mathrm{g}} \quad$ glass transition temperature $\left({ }^{\circ} \mathrm{C}\right)$

$T_{\mathrm{av}} \quad$ film temperature $\left({ }^{\circ} \mathrm{C}\right)$

$t$ time (s)

$u \quad$ moisture in drop (dry basis) ( $\mathrm{kg}$ water $/ \mathrm{kg}$ solid)

$U_{\mathrm{o}} \quad$ Parameter in GAB equation

$x \quad$ mass fraction

$\Delta H_{\mathrm{v}} \quad$ latent heat of vaporization of water $(\mathrm{J} / \mathrm{kg})$

$z, Z$ spatial variables in solute fixed coordinate $(\mathrm{kg})$

$\psi \quad$ dimensionless time

\section{Subscripts}

a related to air

d related to the drop

mixture of mixture

M maltodextrin

$\mathrm{n}$ number of components

o initial value 
sucrose

solid

related to water or solution

\section{References}

[1] K. Masters, Deposit-free spray drying: Dream or reality?, Drying, 96Proceedings of the 10th International Drying Symposium (IDS'96), 30 July-2 August, Krakow, Poland, Vol. 1, pp.52-60.

[2] B.R. Bhandari, N. Datta, R. Crooks, T. Howes, S. Rigby, A semiempirical approach to optimize the quantity of drying aids required to spray dry sugar rich foods, Dry. Technol. 15 (1997) 2509-2525.

[3] C.A. Lockemann, A new laboratory method to characterize the sticking property free flowing solids, Chem. Eng. Process. 38 (1999) 301-306.

[4] M.E. Lazar, A.H. Brown, G.S. Smith, F.F. Wong, F.E. Lindquist, Experimental production of tomato powder by spray drying, Food Technol. 1 (1956) 129-134.

[5] J.G. Brennan, J. Herrera, R. Jowitt, A study of some of the factors affecting the spray drying of concentrated orange juice, on a laboratory scale, Food Technol. 6 (1971) 295-307.

[6] H. Pasley, P. Haloulos, Stickiness - a comparison of test methods and characterization parameters, in: V. Rudolph, R.B. Keey, A.S. Mujumdar (Eds.), Drying '94, vol. 1, 1994, pp. 165-172.

[7] C. Hennigs, T.K. Kockel, T.A.G. Langrish, New measurements of the sticky behavior of skim milk powder, Dry. Technol. 19 (2001) 471-484.

[8] Y. Roos, M. Karel, Phase transition of mixture of amorphous polysaccharides and sugars, Biotechnol. Prog. 7 (1991) 49-53.

[9] B. Adhikari, T. Howes, B.R. Bhandari, V. Troung, Characterization of the surface stickiness of fructose-maltodextrin solutions during drying, Dry. Technol. 21 (2003) 17-34.

[10] B. Adhikari, T. Howes, B.R. Bhandari, V. Troung, In situ characterization of stickiness of sugar-rich foods using a liner actuator driven stickiness testing device, J. Food Eng. 58 (2003) 11-22.

[11] B. Adhikari, T. Howes, B.R. Bhandari, V. Troung, Surface stickiness of drops of carbohydrate and organic acid solutions during convective drying: experiments and modelling, Dry. Technol. 21 (2003) 839-873.

[12] B. Adhikari, T. Howes, B.R. Bhandari, V. Truong, Effect of addition of maltodextrin on drying kinetics and stickiness of sugar and acid-rich foods during convective drying: experiments and modelling, J. Food Eng. 62 (2004) 53-68.

[13] T.A.G. Langrish, D.F. Fletcher, Spray drying of food ingredients and applications of CFD in spray drying, Chem. Eng. Process. 40 (2001) $345-354$.

[14] D.J.E. Harvie, T.A.G. Langrish, D.F. Fletcher, A computational fluid dynamics study of a tall-form spray dryer, Food Bioprod. Process. 80 (C3) (2002) 163-175.
[15] T.A.G. Langrish, D.F. Fletcher, Prospects for the modelling and design of spray dryers in the 21st century, Dry. Technol. 21 (2003) $197-215$.

[16] J. van der Lijn, P.J.A.M. Kerkhof, W.H. Rulkens, Droplet heat and mass transfer under spray-drying conditions, International Symposium on Heat and Mass Transfer Problems in Food Engineering, Wageningen, The Netherlands, 1972, Paper F3.

[17] M. Gordon, J.S. Taylor, Ideal copolymers and the second-order transitions of synthetic rubbers: I. Non-crystalline copolymers, J. Appl. Chem. 2 (1952) 493-500.

[18] B. Adhikari, Drying kinetics and stickiness studies of single drop of sugar and acid-rich solutions, PhD thesis, School of Engineering, The University of Queensland. 2003.

[19] B. Adhikari, T. Howes, B.R. Bhandari, S. Yamamoto, V. Truong, Application of a simplified method based on regular regime approach to determine the effective moisture diffusivity of mixture of low molecular weight sugars and maltodextrin during desorption, J. Food Eng. 54 (2002) 157-165.

[20] S. Yamamoto, A short-cut method for determining concentration dependent diffusivity in liquid foods and polymer solutions from regular regime drying curves, Dry. Technol. 19 (2001) 1479-1490.

[21] S. Yamamoto, Y. Sano, Drying of carbohydrate and protein solutions, Dry. Technol. 13 (1995) 29-41.

[22] K.Ch.A.M. Luyben, J.K. Liou, S. Bruin, Enzyme degradation during drying, Biotechnol. Bioeng. 24 (1982) 534-552.

[23] V. Truong, B.R. Bhandari, T. Howes, B. Adhikari, Analytical model for the prediction of glass transition temperature of food systems, in: H. Levine (Ed.), Amorphous Foods and Pharmaceutical Systems, 2002, pp. 31-47.

[24] V. Truong, Modeling of glass transition temperature of sugar-rich foods and its relation to spray drying of such products. $\mathrm{PhD}$ thesis (2003). School of Land and Food, The University of Queensland, QLD, 4072. Australia.

[25] W.E. Ranz, W.R. Jr. Marshall, Evaporation from drops, AIChE J. 48(1952):141-146 and 173-180.

[26] R.B. Bird, W.E. Stewart, E.N. Lightfoot, Transport Phenomena, John Wiley and Sons, New York, 1960.

[27] E.G. Murakami, M.R. Okos, Measurement and prediction of thermal properties of foods, in: R.P. Singh, A.G. Medina (Eds.), Food Properties and Computer Aided Engineering of Food Processing Systems, Kluwer Academic Publishers, 1989.

[28] Y. Roos, Characterization of food polymers using state diagrams, J. Food Eng. 24 (1995) 339-360.

[29] T. Kudra, Sticky region in drying - definition and identification, Dry. Technol. 21 (2003) 1457-1469.

[30] G.P. Johari, A. Hallbrucker, E. Mayer, The glass liquid transition of hyperquenched water, Nature 330 (1987) 552-553. 